NBER WORKING PAPER SERIES

\title{
ALCOHOL ABUSE AND SUICIDE ATTEMPTS AMONG YOUTH - CORRELATION OR CAUSATION?
}

\author{
Pinka Chatterji \\ Dhaval Dave \\ Robert Kaestner \\ Sara Markowitz \\ Working Paper 9638 \\ http://www.nber.org/papers/w9638
}

NATIONAL BUREAU OF ECONOMIC RESEARCH

1050 Massachusetts Avenue

Cambridge, MA 02138

April 2003

We gratefully acknowledge funding from the Robert Wood Johnson Foundation, Substance Abuse Policy Research Program (Grant Number 43860). We would like to thank Jon Gruber for providing data. The views expressed herein are those of the authors and not necessarily those of the National Bureau of Economic Research.

(C2003 by Pinka Chatterji, Dhaval Dave, Robert Kaestner, and Sara Markowitz. All rights reserved. Short sections of text not to exceed two paragraphs, may be quoted without explicit permission provided that full credit including Cnotice, is given to the source. 
Alcohol Abuse and Suicide Attempts Among Youth - Correlation or Causation?

Pinka Chatterji, Dhaval Dave, Robert Kaestner, and Sara Markowitz

NBER Working Paper No. 9638

April 2003

JEL No. I1

\title{
ABSTRACT
}

This study uses the Youth Risk Behavior Survey (YRBS) and the National Comorbidity Survey (NCS) to explore the causal relationship between alcohol abuse (binge drinking and clinically defined alcohol use disorders) and suicide attempts among youth. We use an empirical approach that allows one to assess the existence and strength of a causal relationship without relying on identifying assumptions. Our results suggest that a causal relationship between binge drinking and suicide attempts is very unlikely. The findings, however, support a causal relationship between clinically defined alcohol use disorders and suicide attempts among girls.

\author{
Pinka Chatterji \\ Dhaval Dave \\ Center for Multicultural Mental Health Research \\ Graduate Center \\ at Cambridge Health Alliance/Harvard Medical Center \\ City University of New York \\ 120 Beacon Street \\ $4^{\text {th }}$ Floor \\ Somerville, MA 02143 \\ Fifth Avenue, $5^{\text {th }}$ Floor \\ New York, NY 10016 \\ ddave@gc.cuny.edu \\ and NBER \\ pchatterji@charesearch.org \\ Robert Kaestner \\ Sara Markowitz \\ Institute of Government and Public Affairs \\ National Bureau of Economic Research \\ University of Illinois at Chicago \\ 815 West Van Buren Street \\ Suite 525 \\ Chicago, IL 60607 \\ and NBER \\ 365 Fifth Avenue, $5^{\text {th }}$ Floor \\ New York, NY 10016 \\ and Rutgers University, Newark \\ smarkow@newark.rutgers.edu \\ kaestner@uic.edu
}




\section{INTRODUCTION}

Recent years have witnessed widespread public concern over the alarming rate of youth suicide, as signaled by the publication of the Surgeon General's Call to Action to Prevent Suicide (US Public Health Service 1999). More young adults die from suicide in the U.S. than from all leading natural causes of death combined, including cancer, heart disease, AIDS, and congenital defects. In 1999, 1,615 teenagers aged 15-19 years old took their own lives, making suicide the third leading cause of death among youth behind accidents and homicides (Centers for Disease Control and Prevention 2002). Suicide attempts are much more common than completed suicide; as many as 150 youths attempt suicide for every completed suicide. ${ }^{1}$ A previous suicide attempt is considered a leading risk factor for completing a suicide. Moreover, suicide attempts, regardless of whether or not they are completed, impose real health care and other costs. The costs associated with both completed and medically treated suicides by youths under 21 amounted to 3.7 billion dollars in 1996 (Children's Safety Network Economic and Insurance Resource Center 2003).

A growing body of research implies that alcohol abuse is an important and independent risk factor for suicide attempts among youth. The strong association between alcohol abuse and suicide attempts is significant from a policy perspective because it suggests that alcohol use prevention policies may be effective tools in reducing suicide attempts and completed suicides among youth. Of course, this possibility depends on whether or not the association between alcohol abuse and suicide attempts is truly causal. No previous study, however, has tested a causal hypothesis directly among youth, either because of reliance on state-level rather than on individual-level data, or because of statistical problems associated with obtaining causal

\footnotetext{
${ }^{1}$ Data from the National Comorbidity Survey, used in this study, indicate that 2 percent of the respondents aged $15-$ 24 reported a suicide attempt in the past year. With a suicide death rate of 13.1 per 100,000 in 1991, this translates
} 
estimates. The absence of such information undermines the formulation of effective public policies.

The objective of this study is to use individual-level data on boys and girls from the Youth Risk Behavior Survey (YRBS) and individual-level data on girls from the National Comorbidity Survey (NCS) to explore the causal relationship between alcohol abuse (including both self-reports about binge drinking and clinically defined alcohol use disorders) and suicide attempts among youth. We use both of these data sets in order to take advantage of the superior binge drinking measures and larger sample size in the YRBS, as well as the rich information on clinical diagnoses and family background in the NCS. To achieve our objective, we use a novel empirical approach, recently proposed by Altonji et al. (2001). There are two parts to this approach. The first step involves obtaining estimates of the effect of alcohol abuse on suicide attempts from a bivariate probit regression model in which the effect of unobservable variables is fixed at various levels. This part of the analysis allows us to gauge how sensitive estimates of the effect of alcohol abuse are to selection on unobserved variables. The second step calculates the amount of selection on observed variables and obtains estimates of the effect of alcohol abuse on suicide attempts under the assumption that the selection on unobserved variables is equal to the selection on observed variables.

The advantage of the Altonji et al. (2001) procedure is that it allows researchers to assess the existence and strength of a causal relationship without requiring the use of identifying assumptions that are often not credible - for example, the existence of valid instruments in an instrumental variables context. As a result, without any other identifying assumptions, researchers can estimate the amount of selection on unobservable factors using the observed

to 153 attempts for every completion. 
data, and in our case identify a lower bound on the causal parameter estimate. ${ }^{2}$

Our results indicate that although self-reports of binge drinking probably do not play a causal role in suicide attempts, clinically defined alcohol use disorders may cause a significant increase in the risk of a suicide attempt, at least among teenage girls. We show that there is considerable selection both into alcohol abuse and into suicide attempts along observable characteristics. This finding implies the existence of at least some degree of selection on unobservable characteristics. Our analysis of constrained bivariate probit models, however, demonstrates that even very modest amounts of selection on unobservable characteristics would eliminate the effect of binge drinking on suicide attempts. This result provides evidence that a causal relationship between binge drinking and suicide attempts is very unlikely. In the case of clinically defined alcohol use disorders, even a large amount of selection on unobservable factors does not completely eliminate the positive effect of clinically defined alcohol use disorders on suicide attempts among girls. This finding supports a causal relationship between clinically defined problem drinking and suicide attempts among girls.

Overall, the results imply that while binge drinking may be an important marker for a youth at elevated risk for a suicide attempt, preventing binge drinking among youth will not be effective in preventing suicide attempts. On the other hand, effective treatment for youth who meet clinical criteria for alcohol abuse or dependence, which may include a significant number of binge drinkers, may reduce the risk of suicide attempts. The prevalence of alcohol use disorders in the general youth population is about $15 \%$, but prevalence rates can be $50 \%$ or higher among special populations of youths, such as juvenile offenders (Martseller et al. 1997; Teplin et al. 2002). Interventions that identify and assist these youths, such as accessible

\footnotetext{
${ }^{2}$ The lower bound is based on the assumption that selection on unobservable variables is no greater than selection on observables. Below, we provide justification for this assumption.
} 
screening and treatment programs, may be more effective in reducing suicide attempts than broader policies, such as responsible drinking programs and minimum legal drinking ages, that are aimed at all youth who use alcohol.

\section{BACKGROUND}

In his classic work on suicide, Durkheim (1951) asserts that the suicide rate is inversely related to the degree of social integration. While his work does not consider the linkage between alcohol and suicide, one can postulate a theoretical link between alcohol abuse and suicide attempts based on this channel. Several studies document that excessive alcohol use leads to a deterioration of social ties. ${ }^{3}$ In addition to this indirect link via social disintegration, more direct ones also have been documented. There is an extensive literature linking alcohol and drug abuse to aggression and violence. ${ }^{4}$ Arguably, suicide is a special class of violence, the result of aggression and violence against oneself rather than against another individual (Dawson 1997). An acute state of intoxication due to alcohol may reduce the individual's self-control, impair cognition, and thereby trigger suicidal tendencies (Norstrom 1995). ${ }^{5}$

Given the plausible mechanisms specified above, numerous social scientists have studied the empirical relationship between alcohol abuse and suicide attempts among young people. In samples of high-risk youth, there is a strong correlation between clinically defined alcohol dependence and abuse and suicide attempts (Deykin \& Buka 1994). Retrospective studies of completed adolescent suicides demonstrate that 12 to $44 \%$ of females and 27 to $42 \%$ of males met diagnostic criteria for a substance use disorder before their deaths (Marttunen et al 1991;

\footnotetext{
${ }^{3}$ See Norstrom (1995) and Rossow and Lauritzen (1999 \& 2001).

${ }^{4}$ See for example Dawson (1997) and Markowitz (2001).

5 Alcohol and drugs are sometimes used by mentally ill individuals to relieve depression and psychological distress (Saffer and Dave, 2002; Gruenwald et al, 1995). However, such self-medication may actually end up exacerbating depression, anxiety, and psychological stress. Other biochemical risk factors such as serotonin depletion may also be aggravated due to alcohol use. Rogers (1992) notes that these effects of alcohol may additionally induce myopia
} 
Shaffer et al 1996). Alcohol abuse also is associated with suicide attempts in non-clinical samples of youth (Workman \& Beer 1990; Wagner et al. 1996; Felts et al.1992).

Despite this strong correlation in both clinical and general population samples, researchers have not established that alcohol use and abuse have causal effects on an adolescent's risk of attempting suicide (Crumley 1990). Alcohol use and abuse often are correlated with other, sometimes hard to measure, determinants of suicide attempts, making it difficult to establish causation. In particular, many researchers report that, in addition to alcohol use disorders, other psychiatric conditions have been linked to suicide attempts among youth, particularly depressive disorders (Deykin and Buka 1994; Shaffer et al. 1996; Runeson, 1990; Crumley, 1990). For example, in a study of teenagers who completed suicide, approximately $61 \%$ appeared to have experienced a clinically significant mood disorder at the time of death, and approximately $35 \%$ appeared to have had a substance use disorder (Shaffer 2000).

Some research has addressed this issue and found that even after controlling for other psychiatric disorders, alcohol abuse remains a strong, independent predictor of suicide attempts. Wagner et al. (1996), for example, note that while co-morbid depression and conduct problems increase the probability that an alcohol abusing youngster attempts suicide, alcohol abuse also independently increases the probability of attempting suicide. Similarly, Cutler et al. (2001) find that among adolescent respondents in the National Longitudinal Study of Adolescent Health, alcohol use is a statistically significant predictor of suicide attempts, after controlling for depression. While offering stronger evidence than other studies that alcohol abuse is a cause of suicide attempts, these studies are still limited by the incomplete measures of co-morbid conditions available in the data. Thus, in the end, these studies remain less than definitive. 
Several recent studies based on state-level data suggest that higher minimum legal drinking ages and higher beer taxes, through their impact on teenage alcohol use, reduce the number of completed suicides among young people. Jones et al. (1992), using state-level data from 1979 to 1984, find that the suicide rate among 15-24 year olds was 9.7\% greater among youth living in states where they could drink legally compared to youth of the same age who lived in states where they could not drink legally. Birckmayer \& Hemenway (1999) find that the suicide rate among $18-20$ year olds was $8 \%$ higher in states with a minimum legal drinking age (MLDA) of 18 years old compared to youth living in states with a MLDA of 21 years old. In contrast to these studies, Hingson et al. (1985) fail to find an association between the minimum legal drinking age in Massachusetts and suicides.

These studies are limited, however, in that none address the issue of causation directly. First, there is the ecological fallacy problem; the existence of an aggregate relationship does not necessarily imply the existence of an individual causal relationship (Greenland \& Robins 1994). Second, these studies are based on reduced form models, which link state-level policies directly to state-level suicide rates. Thus, they do not test the direct relationship between alcohol abuse and suicide and they fail to assess the reasonableness of their findings in terms of the direct effect of alcohol abuse on suicide. For example, Birckmayer and Hemenway (1999) find that minimum legal drinking age laws affected suicide rates of those 18 to 21 and those 21 to 23 years of age, even though minimum drinking age laws are not applicable to persons 21 to 23 years of age. ${ }^{6}$ Third, these studies cannot account for the fact that state minimum drinking age laws are not exogenously determined. It is not random that Louisiana was the last state in the country to raise the minimum drinking age to 21 .

\footnotetext{
${ }^{6}$ Birckmayer and Hemenway (1999) suggest that this is a plausible effect since alcohol use of those 21 to 23 may be affected by minimum legal drinking ages, although there is relatively little evidence to support such a conclusion.
} 
To summarize, there is considerable evidence that alcohol abuse is associated with suicide attempts and completed suicides. However, the non-experimental nature of all of these studies limits their ability to establish a causal relationship. Thus, as is usually the case in social science research, additional study is warranted in order to provide enough evidence so that policy makers can make decisions with confidence using a "weight of the evidence" criterion. In this paper, we extend the literature in this area by using a novel methodology that will significantly add to the weight of evidence on this issue.

\section{ANALYTICAL FRAMEWORK}

Our objective is to assess the existence and strength of a causal relationship between alcohol abuse and suicide attempts. This task is complicated by two factors. The first is what we refer to as statistical endogeneity wherein an individual's suicide attempts and alcohol abuse may depend on a common set of unobserved factors (for example, mental illness or family history). The second is what we refer to as structural endogeneity wherein both outcomes may directly influence each other. For instance, in addition to alcohol abuse causing suicide attempts, a person with suicidal impulses may binge drink to facilitate a suicide attempt.

We begin with a simple, linear specification of the structural production function for suicide attempts $\left(\mathrm{S}_{\mathrm{i}}\right)$ and a demand function for alcohol abuse $\left(\mathrm{A}_{\mathrm{i}}\right):^{7}$

$$
\begin{aligned}
& S_{i}=\alpha_{1} A_{i}+\alpha_{2} X_{i}+\alpha_{3} \mu_{i}+\varepsilon_{i}, \\
& A_{i}=\beta_{1} S_{i}+\beta_{2} X_{i}+\beta_{3} \mu_{i}+\eta_{i} .
\end{aligned}
$$

Equation (1) is a production function for suicide attempts $\left(\mathrm{S}_{\mathrm{i}}\right)$, which is a function of alcohol abuse $\left(\mathrm{A}_{\mathrm{i}}\right)$, observable characteristics that affect suicide attempts such as age, gender, and race $\left(\mathrm{X}_{\mathrm{i}}\right)$, and unobservable characteristics such as personality traits or a social environment that encourages risky behavior $\left(\mu_{\mathrm{i}}\right)$. Equation (2) is the demand for alcohol. The vector $\mathrm{X}_{\mathrm{i}}$ represents 
observed individual characteristics that determine alcohol abuse; these characteristics are the same as the observed determinants of suicide attempts $\left(\mathrm{X}_{\mathrm{i}}\right)$. Similarly, the vector $\mu_{\mathrm{i}}$ represents unobserved determinants of suicide attempts that also may influence alcohol abuse. The subscript i refers to the individual, and $\varepsilon_{\mathrm{i}}$ and $\eta_{\mathrm{i}}$ represent random disturbance terms. Intercepts are suppressed for convenience.

The parameter of interest is $\alpha_{1}$, the structural effect of alcohol abuse on suicide attempts. However, single equation estimation methods, such as Ordinary Least Squares will yield biased estimates for two reasons. To see why, we derive the reduced form demand function for alcohol abuse by substituting equation (1) into equation (2).

$$
\begin{aligned}
& A_{i}=\left(\alpha_{2} \beta_{1} / 1-\alpha_{1} \beta_{1}\right) X_{i}+\left(\beta_{2} / 1-\alpha_{1} \beta_{1}\right) Y_{i}+\left(\alpha_{3} \beta_{1}+\beta_{3} / 1-\alpha_{1} \beta_{1}\right) \mu_{i}+\beta_{1} \varepsilon_{i}+\eta_{i} \\
& A_{i}=\pi_{1} X_{i}+\pi_{2} Y_{i}+\pi_{3} \mu_{i}+\beta_{1} \varepsilon_{i}+\eta_{i}
\end{aligned}
$$

The bias in equation 1 arises if there are common unmeasured factors $\left(\mu_{\mathrm{i}}\right)$ that determine both suicide attempts and alcohol abuse $\left(\alpha_{3} \neq 0\right.$ and $\left.\beta_{3} \neq 0\right)$. In such cases, unmeasured factors are likely to be correlated with alcohol abuse $\left(\pi_{3} \neq 0\right)$. A second reason that alcohol abuse may be correlated with the error term is structural endogeneity, or the possibility that suicide attempts are a determinant of alcohol abuse $\left(\beta_{1} \neq 0\right)$.

\section{ESTIMATION}

Our estimation strategy proceeds in a stepwise fashion. Initially, we ignore the endogeneity problems and estimate equation (1) using a standard probit regression model. We start with a probit model that includes a parsimonious set of covariates. Next, we estimate a

\footnotetext{
${ }^{7}$ This model is derived from the model of violence in Markowitz and Grossman (1998).
} 
probit model with an expanded set of covariates. Estimating both the basic and the extended models allows us to evaluate how much of the association between alcohol abuse and suicide attempts appears to be driven by omitted individual heterogeneity. If the magnitude of the marginal effect of alcohol abuse is highly sensitive to the inclusion of additional covariates, then one could surmise that unobservable factors also play some role in this relationship. This assumption is especially reasonable if one is using a multi-purpose, secondary data set, where the information collected on respondents may not include all information relevant to the outcome under study (Altonji et al. 2001).

In this paper, we call this problem selection on observables and selection on unobservables (Altonji et al. 2001). These two terms are used to acknowledge that teenagers are not sorted randomly into suicidal and drinking behaviors. Selection on observables refers to the existence of observed factors (such as age and race) that are correlated with suicide attempts and with alcohol consumption and will therefore influence the point estimates of the coefficients on alcohol. Selection on unobservables refers to the possible existence of factors that are not available in the survey data and that also may be associated with both alcohol use and suicide attempts (such as family problems). The degree of selection on the observables can be gauged by comparing the estimated coefficients on alcohol abuse that result from the parsimonious and expanded models. Unfortunately, the degree of selection on the unobserved characteristics cannot be measured directly. However, we will attempt to bound this latter effect using an approach proposed by Altonji et al, and thereby draw inferences about the unbiased relationship between alcohol use and suicide attempts.

The observed correlation between alcohol abuse and suicide attempts is likely to be influenced, at least to some degree, by the selection biases discussed above. For this reason, the 
estimated coefficients on alcohol abuse from the extended models may be considered upper bound estimates of the impact of alcohol abuse on suicide attempts. Since we expect that unobservable factors that determine suicide attempts and alcohol abuse are positively correlated, further efforts to control for selection bias only would attenuate the estimated effect of alcohol abuse on suicide attempts.

Selection bias is a common problem in applied social science research. In cases such as ours, previous researchers have used full information maximum likelihood strategies, such as the bivariate probit, to account for the problem. The bivariate probit model is based on the assumption that the unmeasured determinants in equations (1) and (3) have a joint, bivariate normal distribution. This procedure is applicable when suicide attempts $\left(\mathrm{S}_{\mathrm{i}}\right)$ and alcohol abuse $\left(\mathrm{A}_{\mathrm{i}}\right)$ are measured as dichotomous variables. The bivariate probit model obtains estimates of equations (1) and (3) jointly. ${ }^{8}$ But in our case, since the same vector of socioeconomic and demographic factors is included in both equations, identification comes purely from functional form restrictions. In practice, however, such functional form restrictions generally are inadequate and are difficult to defend.

For this reason, as in the case of instrumental variables, implementation of the bivariate probit model requires valid exclusion restrictions - variables that affect alcohol abuse but do not directly affect suicide attempts. However, it is difficult to find valid instruments. A common strategy in models related to ours is to use alcohol prices and alcohol control policies as instruments, but this strategy is often inadequate because the instruments are only weakly

\footnotetext{
${ }^{8} \mathrm{We}$ also could estimate jointly the two structural equations (1) and (2) using the bivariate probit model, which is equivalent to estimating (1) and (3). If the bivariate probit model is applied properly, both should yield a consistent estimate of $\alpha_{1}$. The only difference is that the correlation between the disturbance terms in equations (1) and (3) is greater than that between equations (1) and (2). This difference occurs because the reduced form alcohol abuse equation (3) has netted out the effect of suicide and thus its error $\varepsilon_{\mathrm{i}}$ now also appears as part of the disturbance term in the reduced form alcohol abuse equation.
} 
correlated with alcohol abuse. Under such circumstances, the bivariate probit model performs poorly, yielding estimates with very large standard errors. ${ }^{9}$

We rely on an alternative approach proposed by Altonji et al. (2001) that is based on the bivariate probit model, but does not rely on alcohol control policies as identifying variables. ${ }^{10}$ First, we estimate a bivariate probit model without any identifying assumptions but with a constrained correlation coefficient, $\rho$. We constrain $\rho$ to be 0.10 initially and then examine the effects of increasing $\rho$ in increments of 0.10 to $0.20,0.30,0.40$ and 0.50 . In this way, we impose on the model increasingly greater amounts of (positive) selection on unobservables and examine whether or not the effect of alcohol abuse on suicide attempts is robust to such changes. This analysis allows us to determine the threshold of selection on unobservables, if any, at which alcohol abuse no longer has a statistically significant effect on suicide attempts.

Altonji et al. (2001) argue that if the observable determinants of an outcome are truly just a random sub-set of the complete set of determinants, selection on observable characteristics must be equal to selection on unobservable characteristics. ${ }^{11}$ This assertion of equal selection is unlikely to be true, and in fact, given our specialized data sets, we would expect selection on observable factors to be greater than selection on unobservable factors. Thus, estimates obtained under the assumption of equal selection will be biased downwards. Moreover, there is no theoretical or empirical evidence that alcohol abuse has the potential to inhibit or prevent a

\footnotetext{
${ }^{9}$ See Rashad and Kaestner (2003) for an analysis that illustrates the poor performance of bivariate probit models in such circumstances.

${ }^{10}$ See Grossman et al. (2002), which studies the relationship between adolescent alcohol use and sexual behavior using bivariate probit techniques similar to those used in the present study.

${ }^{11}$ Altonji et al. (2001) show that this condition implies: $\operatorname{cov}\left(S^{*}, X^{\prime} \gamma\right) / \operatorname{var}\left(X^{\prime} \gamma\right)=\operatorname{cov}\left(S^{*}, \varepsilon\right) / \operatorname{var}(\varepsilon)$, where $S^{*}$ is an unobserved, continuous measure of the net benefits from a suicide attempt, $X^{\prime} \gamma$ is the vector of observed variables that affect $S^{*}$ weighted by their corresponding coefficients, and $\varepsilon$ is the unobserved determinants of variables that affect $\mathrm{S}^{*}$ weighted by their relevant coefficients. We observe a suicide attempt $(S=1)$ if $S^{*}$ is positive and no suicide attempt $(\mathrm{S}=0)$ otherwise. Because of very strong selection on some exogenous, observable variables, such as age, we impose this condition excluding variables that are thought to be exogenous (age, gender, race, region, state-level characteristics, and survey year in the YRBS, and age and race in the NCS).
} 
suicide attempt. For this reason, the lower bound estimate is the maximum of zero or the estimate obtained under the assumption that selection on unobservable variables is equal to selection on observables. The upper bound effect is the estimate from the naïve single equation probit model that assumes no selection on unobservable variables.

\section{DATA AND MEASURES}

\section{The Youth Risk Behavior Survey}

The Youth Risk Behavior Survey (YRBS) samples a nationally representative group of teenagers in grades 9-12. Data were collected in 1991, 1993, 1995, 1997 and 1999. In each year, a different group of students numbering between 10,000 and 15,000 is surveyed. The primary strength of the YRBS data set is its large size, which allows us to estimate models separately by gender. Estimating models separately for boys and girls is important because numerous studies indicate that the prevalence of suicide attempts as well as the epidemiology of suicide attempts varies considerably between adolescent females and males. ${ }^{12}$ In total, we use four YRBS samples in the study: (1) all girls ( $\mathrm{N}=29,870)$; (2) all boys $(\mathrm{N}=27,108)$; (3) girls who report any level of alcohol use in the past year $(\mathrm{N}=13,410)$; and (4) boys who report any level of alcohol use in the past year $(\mathrm{N}=13,737)$. By restricting one set of analyses to drinkers - a more homogenous group — we reduce the potential for very high degrees of selection on observed variables. The existence of extremely high levels of selection on observed variables

\footnotetext{
${ }^{12}$ Although completed suicides are much more common among male adolescents, female adolescents are about twice as likely as male adolescents to report suicide attempts. Major depression is a strong predictor of suicide attempt for both girls and boys. However, girls who attempt suicide are more likely to have family dysfunction, low self-esteem, anxiety disorders and to have been sexually abused than boys. Boys who attempt suicide are more likely than girls to report chronic stress, alcohol problems, and financial problems (Beautrais 2002, Weyrauch et al. 2001, Kelly et al. 2001, Wunderlich et al. 2001)
} 
undermines the effectiveness of the bivariate probit models where selection on observed variables is constrained to be equal to selection on unobserved variables. ${ }^{13}$

We measure suicide attempts among YRBS youth using a dummy variable indicating whether or not the respondent reported attempting suicide at least once in the past year. The weighted percentage of respondents attempting suicide in the complete sample (drinkers and non-drinkers) is about 7.5 percent during the sample period. The measure of alcohol abuse is not a clinical diagnosis; clinical information is not available in these data. Instead, we use an indicator of whether or not the respondent had five or more drinks of alcohol in a row within a couple of hours on at least one occasion in the past 30 days. About 31.3 percent of respondents in the complete sample report at least one of these binge drinking episodes in the past month.

The YRBS contains only limited socioeconomic and demographic information on respondents. Only survey year, state of residence, age, grade-level, and gender are consistently reported in all surveys. The availability of state of residence allows us to include the state-level unemployment rate and per capita real state-level income as covariates. These state level variables are included to proxy family and community economic conditions, which are not available in the data. The state characteristics also may capture unobserved attitudes towards risky behaviors that respondents living in the same state might share. The YRBS also does not have information on mental disorders, family background and stressful life events, which are important risk factors for a suicide attempt. However, it does have data on risky behaviors; in particular, the data include an indicator of frequent seat belt use and an indicator for whether or not the respondent is a daily smoker. Many studies have shown that smoking is a strong correlate of psychiatric disorder, although tobacco use is not expected to have a direct impact on

\footnotetext{
${ }^{13}$ A high degree of selection on observable variables implies a very high rho, sometimes greater than 1 , which usually results in the lower bound estimate of the effect to be zero.
} 
suicidal behaviors (Brown et al. 2000; Breslau et al. 1998; Choi et al. 1997). Thus, this variable may be a reasonable proxy for psychiatric disorder. We also include an indicator variable that captures participation on any sports teams, which may reflect the respondent's attachment to and involvement in school and the community.

\section{The National Comorbidity Survey}

Although the YRBS offers a very large sample of adolescents with information on alcohol use and suicide attempts, the data set lacks information on some of the most important correlates of suicide attempts, particularly mental disorders. Moreover, the alcohol use information available in the YRBS does not include a measure of a clinical diagnosis of alcohol abuse or dependence. For this reason, we also estimate all models using The National Comorbidity Survey, a second data set that is very strong in these areas. Our estimates generated from the NCS sample enhance the YRBS analysis in two ways. First, we can evaluate the robustness of the YRBS binge drinking estimates to the inclusion of a much richer set of covariates, which is available in the NCS data. Second, we can examine the association between clinically defined alcohol abuse and dependence and the risk of attempting suicide.

The NCS is a congressionally mandated, nationally representative survey designed to study mental illness in the United States. The survey respondents are 8,098 individuals aged 1554 between 1990 and 1992, with the majority of interviews being conducted in 1991. In order to create a sample that is comparable in terms of age to the YRBS sample, we focus on a subsample of females aged 15-19, resulting in a sample size of 364 individuals. We could not estimate models for 15-19 year old males because only five males reported suicide attempts in 
this age group. In addition, the small sample size precluded limiting the sample to drinkers; instead, we use a combined sample of females that includes drinkers and non-drinkers.

As in the YRBS analysis, we measure suicide attempts using an indicator of whether or not the respondent attempted suicide in the past year. About five percent of NCS respondents report that they attempted suicide at least once during the past year. The rates of suicide attempts in the YRBS and NCS samples are somewhat different, probably because of major differences in the objectives and contexts of the surveys. If we consider suicide attempts that required medical treatment, the rate for NCS females aged 15 to 19 is 3.3\%. The rate of medically treated suicide attempts for YRBS females ages 12 to 18 is $3.0 \%{ }^{14}$ Those rates, therefore, are almost identical. For rates of all female suicide attempts, however, there is a larger difference between the surveys (7.5\% in the YRBS versus $5.0 \%$ in the NCS), apparently because NCS respondents were less likely than YRBS respondents to report suicide attempts that did not require treatment. We conjecture that the NCS respondents tended to only report serious suicide attempts because (1) they were questioned by a trained interviewer collecting information about all of their mental disorders; (2) the NCS instrument is designed to capture serious mental illnesses, unlike the YRBS; and (3) they were asked the questions as a part of a set of very probing questions about mental illness and violence. The YRBS respondents answered questions in the classroom and in the context of questions about all risky behaviors, not mental illness, which may have led them to report all types of suicide attempts rather than just more serious attempts.

We measure alcohol abuse using both a binge drinking measure (as in the YRBS analysis) and a measure that captures clinically defined alcohol use disorders. The binge drinking measure is an indicator of whether or not the respondent consumed five or more drinks

\footnotetext{
${ }^{14}$ We estimated all models with "any medically treated suicide attempt" as the dependent variable. Our results, which are available upon request, were qualitatively very similar to the results for "any suicide attempt" model
} 
on any given day in the past year. We term this binge drinking, though conventionally binge drinking is defined as consuming five or more drinks in a row. About 20.0 percent of NCS respondents report binge drinking in the past year.

The NCS clinical diagnosis of alcohol abuse and/or dependence is generated using the Composite International Diagnostic Interview. The CIDI was developed by the National Institute of Health, the World Health Organization, and the University of Michigan, and is a nonclinician administered instrument, which generates psychiatric diagnoses. The CIDI has undergone extensive testing for reliability and validity. Alcohol abuse is defined as either continued use despite knowledge of its adverse effect on health and social functioning or recurrent use in situations when use may be physically hazardous. Alcohol dependence requires the presence of physiological symptoms of tolerance and withdrawal and continued use despite adverse consequences. We construct a dichotomous indicator that is set equal to one if the respondent met diagnostic criteria for either alcohol abuse or dependence in the past year. About 7.0 percent of the sample met clinical criteria for alcohol abuse or dependence in the past year. The NCS is the only nationally representative survey in the United States to collect detailed data on diagnosed psychiatric disorders, including alcohol use disorders. Controlling for mental illness is crucial in this study because mental illness has been shown to be a significant predictor of both substance use and suicidal behaviors (Saffer and Dave 2002; Crumley 1990; Moscicki 1995). The NCS includes information on 12 non-substance related psychiatric disorders: generalized anxiety disorder; social phobia; simple phobia; panic attack; panic disorder; agoraphobia; post traumatic stress disorder; major depression; dysthymia; bipolar disorder; mania; and non-affective psychosis. The criteria and definitions are based on the Diagnostic and Statistical Manual of Mental Disorders: DSM-III-R (American Psychiatric Association 1988). 
We construct a dichotomous indicator for past year occurrence of any of the 12 psychiatric disorders from this information. ${ }^{15}$

A series of socioeconomic and demographic variables are also defined, including the respondent's age, gender, race, family income, and indicators of religion. Since most of the respondents in our sample have not completed their schooling, we include an indicator of high school dropout, which is set equal to one if the respondent is not in school and has completed less than 12 years of education. An indicator of poor physical health is also defined.

The NCS also includes a rich set of information on family background and life events. Previous studies document that in addition to psychiatric disorders and substance use, suicide attempts also are correlated with family conflict, parental psychiatric disorder, interpersonal difficulties, being a victim of physical or sexual abuse, and other adverse childhood experiences (Brent et al. 2002; Johnson et al. 2002; Glowinski et al. 2001; Dube et al. 2001; Hagedorn \& Omar 2002; Simon et al., 2002; Beitchman et al. 1992). These factors are likely to confound the relationship between substance use and suicide (Rossow and Lauritzen 2001; Cutler et al. 2001). To capture some of these risk factors, we include in the models an indicator of whether or not the respondent lived with both parents until age 15 , and whether or not the respondent lives in an urban area (in a MSA or other urban, non-MSA county). We also include covariates to capture stressful life events such as whether or not the respondent was: (1) involved in a fire or natural disaster; (2) sexually abused, physically abused or neglected as a child; (3) suffered through the death of someone close; (4) witnessed a friend or family member have a major life crisis; and (5) raped during her lifetime. As in the YRBS analysis, we include in the models variables that may

\footnotetext{
${ }^{15} \mathrm{We}$ also ran models that excluded major depressive disorder from our mental illness variables. While suicide ideation and suicide attempts are neither necessary nor sufficient for this diagnosis, they are factors listed under DSM-III-R that may satisfy some of the criteria for major depression. We therefore excluded this disorder since it may introduce spurious correlation between mental illness and the left-hand side suicide variables. Excluding major
} 
capture individual differences in tolerance for risk - whether or not the respondent wears seat belts and whether or not the respondent uses condoms during intercourse.

\section{RESULTS}

Tables 1and 2 show selection into binge drinking and suicide attempts along observable characteristics for the YRBS sample. Tables 3 and 4 show selection into binge drinking, clinically defined alcohol use disorders and suicide attempts for the NCS sample. Tables 5 and 6 summarize results from the standard probit and bivariate probit models estimated using the YRBS sample (Table 5) and the NCS sample (Table 6).

Table 1 presents means and standard errors by binge drinking status for all females, all males, female drinkers and male drinkers from the YRBS. These descriptive statistics show that the observed characteristics differ greatly based on binge drinking status, thus providing evidence that there exists important selection into alcohol abuse along observable characteristics. For example, among both girls and boys in the YRBS sample (Table 1), avoiding seat belt use, carrying a weapon, getting into physical fights and smoking every day are much more prevalent among binge drinkers than among teenagers who do not binge drink. These behaviors also are much more prevalent among those who have attempted suicide, as seen in Table 2. The striking, observable differences between alcohol abusers and non-abusers, and those who do and do not attempt suicide, suggest that selection into suicidal and drinking behaviors based on unobservable factors may be important in the analysis of the YRBS sample. Our assumption of positive selection on unobserved factors is buttressed by the fact that the set of observable risky behaviors (i.e. no seat belt use, weapon-carrying, smoking, fighting) increases the probability of

depression, however, does not significantly alter our results. 
both binge drinking and attempting suicide. This positive selection remains strong even when the samples are limited to drinkers.

These observations also hold true to some extent for the NCS sample, as seen in Tables 3 and 4. There is considerable, positive sorting into alcohol use disorders along observable characteristics such as mental illness, living with both parents until age 15 , and stressful life events, such as having a close relative die (Table 3). Similar selection is observed for suicide attempts (Table 4). Once again, this evidence strongly supports our assumption of positive selection in the constrained bivariate probit models. That is, individuals who meet diagnostic criteria for a psychiatric disorder, who did not live with both parents before age 15 , and have experienced the death of a close family member are more likely to both attempt suicide and to abuse alcohol. We do not find strong selection into binge drinking, which may be due to our use of a non-standard measure of binge drinking. Because of data limitations in the NCS, we define binge drinking as "five or more drinks on any given day in the past year" instead of "five or more drinks in a row within a couple of hours on at least one occasion in the past 30 days," as we did in the YRBS analysis. The latter measure is preferred because it better captures intense drinking by stipulating that the drinks were consumed "in a row", "within a couple hours" and "on one occasion." Moreover, a 30-day measure is superior to a past-year measure because it maximizes the potential for accurate recall.

Table 5 summarizes results from the suicide attempts models based on the YRBS sample. The first row of Table 5 presents the marginal effects and t-ratios on binge drinking from a parsimonious probit model that includes only a small set of covariates, and from a model that includes a more extensive set of variables. The models are estimated separately for all boys and all girls, as well for boys who drink and girls who drink. An F-test (reported in Table 5) of 
all covariates interacted with gender from a fully interacted model empirically supports our estimation based on gender specific samples.

In all of the probit models, the estimates indicate that binge drinking has a statistically significant association with attempting suicide. Estimates from models with an extended set of covariates indicate that binge drinking is associated with a $62 \%$ increase in the probability of suicide attempt for girls and a $40 \%$ increase for boys at the sample means. When the samples are limited to drinkers, binge drinking is associated with an increase in the probability of a suicide attempt by $37 \%$ for girls and $33 \%$ for boys at the sample means. These estimates can be considered upper bound estimates since the model is based on the assumption that binge drinking is exogenous, and both theory and empirical evidence indicate that positive selection on unobserved variables will diminish this effect. In all cases, however, the magnitude of the binge drinking effect is considerably smaller when the full set of covariates, rather than the small set of covariates, is included in the model. This finding indicates strong selection on observable characteristics; the additional covariates included in the more inclusive models are both significant predictors of suicide attempts and are highly correlated with binge drinking.

Given the evidence that selection on observable characteristics is important, and therefore unobservable variables are likely to be important as well, we attempt to assess the degree of selection of unobservable variables that would be needed to reduce or even eliminate the large, statistically significant association between binge drinking and suicide attempts. Table 5 shows estimates of the association between binge drinking and suicide attempts from six bivariate probit models (Models 1-6) estimated using the YRBS samples (all girls, all boys, girl drinkers, boy drinkers). In the first five models, the correlation coefficient $\rho$ is constrained to be $0.1,0.2$, $0.3,0.4$ or 0.5 , with larger coefficients corresponding to stronger correlation between the 
unobservable determinants of alcohol abuse and suicide attempts. In the sixth model, the $\rho$ is constrained such that the degree of selection on unobservable factors is forced to be equal to the degree of selection on observable covariates, which is the highest degree of selection on unobservables that we would expect to encounter. The assumption of positive selection is clearly justified based on the evidence in Tables 1 and 2.

As models (1)-(5) clearly show, even a very modest amount of selection on unobservable variables ( $\rho=0.1$ or 0.2 ) completely eliminates the positive effect of binge drinking on suicide attempts in all four YRBS samples. In fact, as we increase the amount of correlation in increments of 0.10 , the estimated coefficient on binge drinking quickly becomes statistically insignificant, and eventually negative and statistically significant. If we assume that the true lower bound effect is non-negative, which seems appropriate given that there is little reason to expect binge drinking to lower suicide attempts, then the only relevant range of selection on unobserved variables is where the association between binge drinking and suicide attempts is positive. As noted, this occurs when rho takes on a value between 0.1 and 0.2 , suggesting that it is unlikely that binge drinking has a true causal effect. This inference is further supported by the estimates from model (6), which reveal a significant amount of selection on observed variables, as measured by the estimates of rho; indeed, when the sample is not restricted to drinkers, the estimate of rho is outside the feasible range. Thus, in order for binge drinking to have a true positive causal effect on suicide attempts, selection on unobserved variables would have to be close to zero, or only a fraction (10 to 15 percent) of the amount of selection on observed variables. This appears unlikely, especially since we believe that many important, unobserved determinants of suicide attempts and binge drinking remain in the error term. 
Table 6 presents results from the same estimation approach with the NCS sample; the results pertain to females only because of the small sample sizes and the low incidence rate of suicide attempts among males in the NCS data. In this analysis, we consider the effects of binge drinking as well as clinically defined substance use disorders on suicide attempts. As in the YRBS analysis, estimation of small and more fully specified models indicates that selection on observed factors is important since the coefficients fall by $89 \%$ and $79 \%$ for binge drinking and alcohol use disorder, respectively. The more fully specified models indicate that binge drinking is associated with an increase in the probability of suicide attempt of about $17 \%$, while a diagnosis of an alcohol use disorder is associated with an increase in the probability of suicide attempt of $79 \%$ at the sample means. These estimates are our upper bound estimates of the effect of alcohol abuse on suicide attempts. The estimate of the effect of binge drinking on girls' suicide attempts is somewhat smaller than the estimate generated from the analysis of YRBS girls. This is expected given that the binge drinking measure defined in the YRBS is more likely to capture intense drinking occasions.

When we estimate the constrained bivariate probit models, the NCS analysis of binge drinking yields similar results to the YRBS analysis of binge drinking (Table 6). As we increase the amount of positive selection imposed on the model, the association between binge drinking and suicide attempt quickly becomes less positive and statistically insignificant and eventually becomes negative in sign and not statistically significant. As in the YRBS analysis, even small amounts of positive selection on unobserved factors eliminate the positive, statistically significant effect of binge drinking on suicide attempt that we find in the standard probit models.

However, the same exercise yields very different results when we use the NCS sample to consider the effect of clinically defined alcohol use disorders on suicide attempts (Table 6). As 
we impose increasingly greater amounts of positive selection on the bivariate probit model, the effect of alcohol use disorder on suicide attempt grows smaller, as expected, but remains statistically significant, even when the correlation coefficient is constrained to be 0.4 . Second, when selection on unobserved variables is set equal to selection on observed variables, the estimate remains positive and statistically significant. Estimates from model (6) indicate that a diagnosis of an alcohol use disorder increases the probability of a suicide attempt by about 27 percent. The estimated correlation coefficient in the equal selection model is considerably larger than the correlation coefficient estimated in the binge drinking analysis ( 0.307 versus 0.189$)$, which suggests that selection along observed factors is more important for clinically defined alcohol use disorders than for binge drinking. This result is consistent with Tables 3 and 4 .

Because the NCS was conducted specifically to study the determinants of mental illness, it is very unlikely that selection on unobservable factors is equal to selection on observables; in other words, the covariates we can observe, such as mental illness or family background, are likely to be the most important determinants of suicide attempts. Our lower bound, therefore, is extremely conservative. Nevertheless, if we use this estimate as a lower bound on the effect and the standard probit estimate as the upper bound, we conclude that clinically defined alcohol use disorders increase the probability of suicide attempt, and the magnitude of this effect falls between 27 percent and 79 percent. This range is broad, as there is no way of knowing how much selection on unobservable factors exists. However, this range provides strong reason to believe that the relationship between clinically defined alcohol use disorders and suicide attempts is indeed causal, and that the magnitude of this effect is meaningful from a policy perspective, at least among adolescent girls.

\section{DISCUSSION}


Previous research supports a causal relationship between alcohol use and suicide attempts, and suggests that state-level alcohol policies, such as minimum drinking ages, beer taxes and driving while intoxicated laws, can reduce suicide attempts and completed suicide rates among youth. This study tests the plausibility of this idea by using two data sources to explore the causal relationship between alcohol abuse and suicide attempts among youth. We find little evidence that binge drinking and suicide attempts are causally related. This finding implies that broad-based alcohol use policies and prevention programs will not be very effective in reducing suicide attempts among youth. Clearly, more research is needed to reconcile these competing findings and to provide policy makers with a more definitive base of evidence.

However, our study supports the existence of a causal link between clinically defined alcohol use disorders and suicide attempts among female adolescents. Therefore, identifying and treating girls who meet diagnostic criteria for alcohol abuse or dependence may be an effective way to reduce the risk of suicide attempts among youth. To date, there is very little evidence that any existing suicide prevention policies actually reduce the risk of suicide. This research suggests that suicide prevention policies may be useful if they focus on moving substance abusing and dependent youth into effective treatment. 


\section{REFERENCES}

Altonji, JG, Elder, TE, Taber, CR. Selection on observed and unobserved variables: Assessing the effectiveness of Catholic Schools. Working Paper, April 30, 2001.

American Psychiatric Association Task Force (1988). Diagnostic and Statistical Manual of Mental Disorders: DSM-III-R. Washington, D.C., American Psychiatric Association.

Beautrais AL. Gender issues in youth suicidal behavior. Emergency Medicine. 2002; 14: 35-42.

Beitchman JH, Zucker KJ, Hood JE, DaCosta GA et al. A review of the long-term effects of child sexual abuse. Child Abuse \& Neglect. 1992; 16: 101-118.

Birckmayer, J, Hemenway, D. Minimum-age drinking laws and youth suicide, 1970-1990. American Journal of Public Health. 1999; 89: 1365-1368.

Brent, DA. Suicide and suicidal behavior in children and adolescents. Pediatrics in Review. 1989; 10: 269-275.

Brent DA, Oquendo M, Birmaher B, Greenhill L, Kolko D, Stanley B, Zelazby J, Brodsky B, Bridge J, Ellis S, Mann JJ. Familial pathways to early-onset suicide attempt: risk for suicidal behavior in offspring of mood-disordered suicide attempters. Archives of General Psychiatry. 2002;59:801-7.

Breslau, N., Peterson, E.L., Schultz, L.R., Chilcoat, H.D., Andreski, P., 1998. Major depression and stages of smoking: A longitudinal investigation. Archives of General Psychiatry, 55, 161-166.

Brown, C., Madden, P.A.F., Palenchar, D.R., Cooper-Patrick, L. The association between depressive symptoms and cigarette smoking in an urban primary care sample. International Journal of Psychiatry in Medicine, 30, 2000, 15-26.

Centers for Disease Control \& Prevention, National Center for Injury Prevention \& Control website, http://webapp.cdc.gov/sasweb/ncipc/leadcaus.html, Accessed 4/19/02.

Children's Safety Network Economics and Insurance Resource Center website, http://www.csneirc.org/index.html, Accessed 3/03.

Choi, W.S., Patten, C.A., Gillin, J.C., Kaplan, R.M., Pierce, J.P. Cigarette smoking predicts development of depressive symptoms among U.S. adolescents. Annals of Behavioral Medicine, 19, 1997, 42-50.

Crumley, FE. Alcohol abuse and adolescent suicidal behavior. JAMA. 1990; 263: 3051-3056.

Cutler D, Glaeser EL, \& Norberg KE. "Explaining the Rise in Youth Suicide" in Risky Behavior Among Youths-An Economic Analysis, edited by Jonathan Gruber, Chicago, University of Chicago Press, 2001.

Dawson, D. Alcohol, Drugs, Fighting and Suicide Attempt/Ideation. Addiction Research. 1997. $5: 6$, p. 451 .

Deykin, EY, Buka, SL. Suicidal ideation and attempts among chemically dependent adolescents. American Journal of Public Health. 1994; 4: 634-639. 
Dube SR, Anda RF, Felitti VJ, Chapman DP, Williamson DF, Giles WH. Childhood abuse, household dysfunction, and the risk of attempted suicide throughout the life span: findings from the Adverse Childhood Experiences Study JAMA 2001;286:3126-7.

Durkheim, E. (1951). Suicide (J. A. Spaulding \& G. Simpson, Trans.). Glencoe, IL: Free Press.

Felts, WM, Chenier, T, Barnes, R. Drug abuse and suicide ideation and behavior among North Carolina public school students. American Journal of Public Health. 1992; 82: 870-872.

Glowinski AL, Bucholz KK, Nelson EC, Fu Q, Madden PA, Reich W, Heath AC. Suicide attempts in an adolescent female twin sample. Journal of the American Academy of Child \& Adolescent Psychiatry 2001;40:1300-7.

Greenland S and Robins J. 1994. "Invited Commentary: Ecologic Studies-Biases, Misconceptions, and Counterexamples." American Journal of Epidemiology, 139:747760

Grossman M, Kaestner R, and Markowitz S. "Get High and Get Stupid: The Effect of Alcohol and Marijuana Use on Teen Sexual Behavior.” NBER Working Paper No. 9216. National Bureau of Economic Research, September 2002.

Gruenwald, P. and Ponicki, W. "Suicide Rates and Alcohol Consumption in the United States, 1970-1989." Addiction, August 1995, 90:8, p. 1063.

Hagedorn J, Omar H. Retrospective analysis of youth evaluated for suicide attempt or suicidal ideation in an emergency room setting. International Journal of Adolescent Medicine \& Health. 2002; 14: 55-60.

Hingson R, Merrigan D, Heeren T. Effects of Massachusetts raising its legal drinking age from 18 to 20 on deaths from teenage homicide, suicide and nontraffic accidents. Pediatric Clinics of North America. 1985; 32: 221-32.

Johnson JG, Cohen P, Gould MS, Kasen S, Brown J, Brook JS. Childhood adversities, interpersonal difficulties, and risk for suicide attempts during late adolescence and early adulthood. Archives of General Psychiatry 2002;59:741-749.

Jones, NE, Pieper, CF, Robertson, LS. The effect of legal drinking age on fatal injuries of adolescents and young adults. American Journal of Public Health. 1992; 82: 112-115.

Kelly TM, Lynch KG, Donovan JE, Clark DB. Alcohol use disorders and risk factor interactions for adolescent suicidal ideation and attempts. Suicide \& Life-Threatening Behavior. 2001; 31: 181-93.

King, RA, Schwab-Stone, M, Flisher, A, Greenwald, S, Kramer, R, Goodman, S, Lahey, B, Shaffer, D, Gould, M. Psychosocial and risk behavior correlates of youth suicide attempts and suicide ideation. 2001; 40: 837-846.

Lewinsohn PM, Rodhe P, Seeley JR, Baldwin CL. Gender differences in suicide attempts from adolescence to young adulthood. Journal of the American Academy of Child and Adolescent Psychiatry. 2001; 40:427-434. 
Markowitz, S. "The Role of Alcohol and Drug Consumption in Determining Physical Violence and Weapon Carrying by Teenagers," Eastern Economic Journal, 27, No. 4 (Fall 2001), 409-432.

Markowitz, S and Grossman, M. "Alcohol Regulation and Domestic Violence Towards Children," Contemporary Economic Policy, 16, No. 3 (July, 1998), 309-320.

Marsteller FA, Brogan D, Smith I, Ash P, Daniels D, Rolka D, Falek A. The prevalence of alcohol abuse disorders among juveniles admitted to regional youth detention centers operated by the Georgia Department of Children and Youth Services. March 31,1997. Accessed http://www.emory.edu/WHSC/MED/PSYCHIATRY/popstud/CSATFinalReport.htm

Marttunen, MJ, Hillevi, MA, Henriksson, MM, Lonnqvist, JK. Mental disorders in adolescent suicide: DSM-III-R Axes I and II diagnoses in suicides among 13 to 19 year olds in Finland. Archives of General Psychiatry. 1991; 48: 834-839.

Moscicki, EK. "Epidemiology of suicidal behavior." Suicide and life-threatening behavior. 1995; 24: 22-35

Norstrom, T. Alcohol and Suicide: A Comparative Analysis of France and Sweden. Addiction. 1995. 90:11 p1463.

Rashad, I, and Kaestner, R. "Teenage Sex, Drugs and Alcohol: Risky Behaviors and Risky Econometric Methods". Working Paper, January 2003.

Rogers, J. R. Suicide and Alcohol: Conceptualizing the Relationship from a Cognitive-Social Paradigm. Journal of Counseling \& Development. 1992. 70:4 p. 540.

Rossow I. Lauritzen G. Shattered childhood: a key issue in suicidal behavior among drug addicts?. Addiction. 96(2):227-40, February 2001

Runeson, B. Psychoactive alcohol abuse disorder in youth suicide. Alcohol and Alcoholism. 1990; 25: 561-568.

Saffer, H and D. Dave. "Mental Illness and the Demand for Alcohol, Cocaine, and Cigarettes." NBER Working Paper 8699. January 2002

Shaffer, D, Gould, MS, Fisher, P, Trautman, P, Moreau, D, Kleinman, M, Flory, M. Psychiatric diagnosis in child and adolescent suicide. Archives of General Psychiatry. 1996; 53: 339-348.

Shaffer, D. Teen suicide. Department of Child Psychiatry, New York State Psychiatric Institute, Columbia College of Physicians and Surgeons, March 2000.

Simon TR, Anderson M, Thompson MP, Crosby A, Sacks JJ. Assault victimization and suicidal ideation of behavior within a national sample of US adults. Suicide \& Life-Threatening Behavior 2002; 31: 42-50.

Teplin LA. Abram KM. McClelland GM. Dulcan MK. Mericle AA. Psychiatric disorders in youth in juvenile detention. Archives of General Psychiatry. 59(12):1133-43, 2002 Dec.

US Public Health Service, The Surgeon General's Call to Action to Prevent Suicide. Washington DC, 1999. 
Wagner, BM, Cole, RE, Schwartzman, P. Comorbidity of symptoms among junior and senior high school suicide attemptors. Suicide and life-threatening behavior. 1996: 26:300-307.

Weyrauch KF, Roy-Byrne P, Katon W, Wilson L. Stressful life events and impulsiveness in failed suicide. Suicide \& Life-Threatening Behavior. 2001; 31: 311-319.

Workman, M, Beer, J. Relationship between alcohol dependency and suicide ideation among high school students. Psychological Reports. 1990; 66:1363-1366.

Wunderlich U, Bronisch T, Wittchen HU, Carter R. Gender differences in adolescents and young adults with suicidal behavior. Acta Psychiatrica Scandinavica. 2001; 194: 332339. 


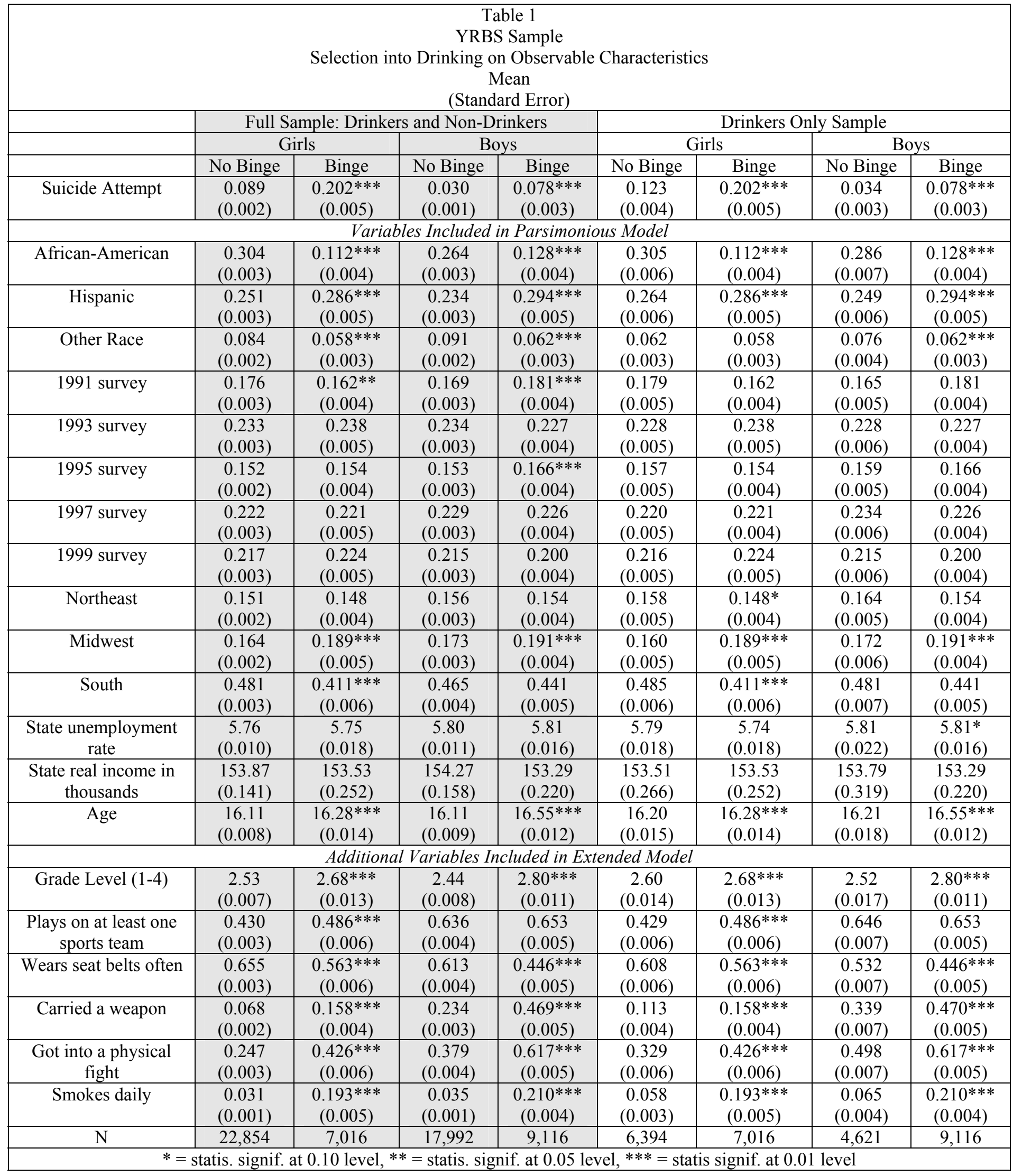




\begin{tabular}{|c|c|c|c|c|c|c|c|c|}
\hline \multicolumn{9}{|c|}{$\begin{array}{c}\text { Table 2 } \\
\text { YRBS Sample } \\
\text { Selection into Suicide Attempt on Observable Characteristics } \\
\text { Mean } \\
\text { (Standard Error) }\end{array}$} \\
\hline & \multicolumn{4}{|c|}{ Full Sample: Drinkers and Non-Drinkers } & \multicolumn{4}{|c|}{$\begin{array}{c}\text { Drinkers Only Sample } \\
\end{array}$} \\
\hline & \multicolumn{2}{|c|}{ Girls } & \multicolumn{2}{|c|}{ Boys } & \multicolumn{2}{|c|}{ Girls } & \multicolumn{2}{|c|}{ Boys } \\
\hline & No Attempt & Attempt & $\begin{array}{c}\text { No } \\
\text { Attempt }\end{array}$ & Attempt & No Attempt & Attempt & No Attempt & Attempt \\
\hline Binge & $\begin{array}{c}0.212 \\
(0.003)\end{array}$ & $\begin{array}{c}0.410 * * * \\
(0.008)\end{array}$ & $\begin{array}{c}0.325 \\
(0.003) \\
\end{array}$ & $\begin{array}{c}0.573^{* * *} \\
(0.014)\end{array}$ & $\begin{array}{c}0.500 \\
(0.005) \\
\end{array}$ & $\begin{array}{c}0.642 * * * \\
(0.010)\end{array}$ & $\begin{array}{c}0.653 \\
(0.004) \\
\end{array}$ & $\begin{array}{c}0.819^{* * *} \\
(0.013)\end{array}$ \\
\hline \multicolumn{9}{|c|}{ Variables Included in Parsimonious Model } \\
\hline African-American & $\begin{array}{c}0.267 \\
(0.003)\end{array}$ & $\begin{array}{c}0.198 * * * \\
(0.007)\end{array}$ & $\begin{array}{c}0.221 \\
(0.003)\end{array}$ & $\begin{array}{c}0.151 * * * \\
(0.010)\end{array}$ & $\begin{array}{c}0.214 \\
(0.004)\end{array}$ & $\begin{array}{c}0.154^{* * * *} \\
(0.008)\end{array}$ & $\begin{array}{c}0.185 \\
(0.003)\end{array}$ & $\begin{array}{c}0.130 * * * \\
(0.011)\end{array}$ \\
\hline Hispanic & $\begin{array}{c}0.249 \\
(0.003)\end{array}$ & $\begin{array}{c}0.338 * * * \\
(0.008)\end{array}$ & $\begin{array}{c}0.250 \\
(0.003)\end{array}$ & $\begin{array}{c}0.339 * * * \\
(0.013)\end{array}$ & $\begin{array}{c}0.259 \\
(0.004)\end{array}$ & $\begin{array}{c}0.360 * * * \\
(0.010)\end{array}$ & $\begin{array}{c}0.274 \\
(0.004)\end{array}$ & $\begin{array}{c}0.348^{* * * *} \\
(0.016)\end{array}$ \\
\hline Other Race & $\begin{array}{c}0.074 \\
(0.002) \\
\end{array}$ & $\begin{array}{c}0.107 * * * \\
(0.005)\end{array}$ & $\begin{array}{c}0.079 \\
(0.002) \\
\end{array}$ & $\begin{array}{c}0.124 * * * \\
(0.010)\end{array}$ & $\begin{array}{c}0.054 \\
(0.002)\end{array}$ & $\begin{array}{c}0.090^{* * * *} \\
(0.006)\end{array}$ & $\begin{array}{c}0.064 \\
(0.002) \\
\end{array}$ & $\begin{array}{c}0.113^{* * *} \\
(0.011) \\
\end{array}$ \\
\hline 1991 survey & $\begin{array}{c}0.175 \\
(0.002)\end{array}$ & $\begin{array}{c}0.157 * * * \\
(0.006)\end{array}$ & $\begin{array}{c}0.174 \\
(0.002)\end{array}$ & $\begin{array}{c}0.141^{* * *} \\
(0.010)\end{array}$ & $\begin{array}{c}0.173 \\
(0.004)\end{array}$ & $\begin{array}{c}0.154 * * \\
(0.008)\end{array}$ & $\begin{array}{c}0.178 \\
(0.003)\end{array}$ & $\begin{array}{c}0.138^{* * *} \\
(0.012)\end{array}$ \\
\hline 1993 survey & $\begin{array}{c}0.231 \\
(0.003) \\
\end{array}$ & $\begin{array}{c}0.258 * * * \\
(0.007)\end{array}$ & $\begin{array}{c}0.230 \\
(0.003) \\
\end{array}$ & $\begin{array}{c}0.257 * * \\
(0.012)\end{array}$ & $\begin{array}{c}0.231 \\
(0.004) \\
\end{array}$ & $\begin{array}{l}0.247^{*} \\
(0.009) \\
\end{array}$ & $\begin{array}{c}0.226 \\
(0.004) \\
\end{array}$ & $\begin{array}{c}0.248 \\
(0.015) \\
\end{array}$ \\
\hline 1995 survey & $\begin{array}{c}0.151 \\
(0.002)\end{array}$ & $\begin{array}{c}0.165 * * \\
(0.006)\end{array}$ & $\begin{array}{c}0.157 \\
(0.002)\end{array}$ & $\begin{array}{c}0.162 \\
(0.010)\end{array}$ & $\begin{array}{c}0.153 \\
(0.003)\end{array}$ & $\begin{array}{l}0.169^{*} \\
(0.008)\end{array}$ & $\begin{array}{c}0.163 \\
(0.003)\end{array}$ & $\begin{array}{c}0.171 \\
(0.013)\end{array}$ \\
\hline 1997 survey & $\begin{array}{c}0.221 \\
(0.003)\end{array}$ & $\begin{array}{c}0.218 \\
(0.007)\end{array}$ & $\begin{array}{c}0.228 \\
(0.003)\end{array}$ & $\begin{array}{c}0.232 \\
(0.012)\end{array}$ & $\begin{array}{c}0.218 \\
(0.004)\end{array}$ & $\begin{array}{c}0.232 \\
(0.009)\end{array}$ & $\begin{array}{c}0.228 \\
(0.004)\end{array}$ & $\begin{array}{c}0.239 \\
(0.014)\end{array}$ \\
\hline 1999 survey & $\begin{array}{c}0.221 \\
(0.003)\end{array}$ & $\begin{array}{c}0.202 * * * \\
(0.007)\end{array}$ & $\begin{array}{c}0.210 \\
(0.003)\end{array}$ & $\begin{array}{c}0.207 \\
(0.011)\end{array}$ & $\begin{array}{c}0.225 \\
(0.003)\end{array}$ & $\begin{array}{c}0.171^{* * *} \\
(0.008)\end{array}$ & $\begin{array}{c}0.205 \\
(0.004)\end{array}$ & $\begin{array}{c}0.204 \\
(0.014)\end{array}$ \\
\hline Northeast & $\begin{array}{c}0.149 \\
(0.002)\end{array}$ & $\begin{array}{c}0.159 \\
(0.006)\end{array}$ & $\begin{array}{c}0.154 \\
(0.002)\end{array}$ & $\begin{array}{c}0.181 * * * \\
(0.011)\end{array}$ & $\begin{array}{c}0.149 \\
(0.003)\end{array}$ & $\begin{array}{c}0.171 * * * \\
(0.008)\end{array}$ & $\begin{array}{c}0.155 \\
(0.003)\end{array}$ & $\begin{array}{c}0.187 * * * \\
(0.013)\end{array}$ \\
\hline Midwest & $\begin{array}{c}0.174 \\
(0.002)\end{array}$ & $\begin{array}{c}0.140 * * * \\
(0.006)\end{array}$ & $\begin{array}{c}0.180 \\
(0.002)\end{array}$ & $\begin{array}{c}0.156^{* *} \\
(0.010)\end{array}$ & $\begin{array}{c}0.181 \\
(0.004)\end{array}$ & $\begin{array}{c}0.142 * * * \\
(0.007)\end{array}$ & $\begin{array}{c}0.186 \\
(0.003) \\
\end{array}$ & $\begin{array}{c}0.155^{* * *} \\
(0.012) \\
\end{array}$ \\
\hline South & $\begin{array}{c}0.465 \\
(0.003)\end{array}$ & $\begin{array}{c}0.460 \\
(0.008)\end{array}$ & $\begin{array}{c}0.457 \\
(0.003)\end{array}$ & $\begin{array}{c}0.451 \\
(0.014)\end{array}$ & $\begin{array}{c}0.449 \\
(0.005)\end{array}$ & $\begin{array}{c}0.432 \\
(0.011)\end{array}$ & $\begin{array}{c}0.455 \\
(0.004)\end{array}$ & $\begin{array}{c}0.443 \\
(0.017)\end{array}$ \\
\hline $\begin{array}{l}\text { State unemployment } \\
\text { rate }\end{array}$ & $\begin{array}{c}5.74 \\
(0.010)\end{array}$ & $\begin{array}{l}5.91 * * * \\
(0.026)\end{array}$ & $\begin{array}{c}5.81 \\
(0.009)\end{array}$ & $\begin{array}{c}5.89 \\
(0.042)\end{array}$ & $\begin{array}{c}5.74 \\
(0.014)\end{array}$ & $\begin{array}{l}5.88^{* * *} \\
(0.033)\end{array}$ & $\begin{array}{c}5.96 \\
(0.015)\end{array}$ & $\begin{array}{c}6.04 \\
(0.056)\end{array}$ \\
\hline $\begin{array}{c}\text { State real income in } \\
\text { thousands }\end{array}$ & $\begin{array}{l}153.79 \\
(0.131)\end{array}$ & $\begin{array}{l}153.73 \\
(0.365)\end{array}$ & $\begin{array}{l}153.89 \\
(0.132)\end{array}$ & $\begin{array}{c}155.09 * * \\
(0.610)\end{array}$ & $\begin{array}{l}153.32 \\
(0.200)\end{array}$ & $\begin{array}{l}154.50 \\
(0.456)\end{array}$ & $\begin{array}{l}153.37 \\
(0.187)\end{array}$ & $\begin{array}{l}154.76 \\
(0.731)\end{array}$ \\
\hline Age & $\begin{array}{c}16.18 \\
(0.008)\end{array}$ & $\begin{array}{c}16.00 * * * \\
(0.020)\end{array}$ & $\begin{array}{c}16.25 \\
(0.008) \\
\end{array}$ & $\begin{array}{c}16.30 \\
(0.034) \\
\end{array}$ & $\begin{array}{c}16.30 \\
(0.011) \\
\end{array}$ & $\begin{array}{c}15.96^{* * *} \\
(0.025)\end{array}$ & $\begin{array}{c}16.44 \\
(0.010)\end{array}$ & $\begin{array}{c}16.32 * * * \\
(0.041)\end{array}$ \\
\hline \multicolumn{9}{|c|}{ Additional Variables Included in Extended Model } \\
\hline Grade Level (1-4) & $\begin{array}{c}2.59 \\
(0.007)\end{array}$ & $\begin{array}{l}2.35 * * * \\
(0.018)\end{array}$ & $\begin{array}{c}2.57 \\
(0.007)\end{array}$ & $\begin{array}{l}2.49 * * \\
(0.032)\end{array}$ & $\begin{array}{c}2.70 \\
(0.010)\end{array}$ & $\begin{array}{l}2.33^{* * *} \\
(0.023)\end{array}$ & $\begin{array}{c}2.72 \\
(0.010)\end{array}$ & $\begin{array}{l}2.52 * * * \\
(0.037)\end{array}$ \\
\hline $\begin{array}{l}\text { Plays on at least one } \\
\text { sports team }\end{array}$ & $\begin{array}{c}0.444 \\
(0.003)\end{array}$ & $\begin{array}{c}0.443 \\
(0.008)\end{array}$ & $\begin{array}{c}0.645 \\
(0.003)\end{array}$ & $\begin{array}{c}0.569 * * * \\
(0.014)\end{array}$ & $\begin{array}{c}0.460 \\
(0.005)\end{array}$ & $\begin{array}{c}0.452 \\
(0.011)\end{array}$ & $\begin{array}{c}0.655 \\
(0.004)\end{array}$ & $\begin{array}{c}0.577 * * * \\
(0.017)\end{array}$ \\
\hline Wears seat belts often & $\begin{array}{c}0.643 \\
(0.003) \\
\end{array}$ & $\begin{array}{c}0.560^{* * * *} \\
(0.008)\end{array}$ & $\begin{array}{c}0.562 \\
(0.003) \\
\end{array}$ & $\begin{array}{c}0.455^{* * *} \\
(0.014)\end{array}$ & $\begin{array}{c}0.596 \\
(0.005) \\
\end{array}$ & $\begin{array}{c}0.527 * * * \\
(0.011)\end{array}$ & $\begin{array}{c}0.480 \\
(0.004)\end{array}$ & $\begin{array}{c}0.394^{* * *} \\
(0.017) \\
\end{array}$ \\
\hline Carried a weapon & $\begin{array}{c}0.073 \\
(0.002)\end{array}$ & $\begin{array}{c}0.211 * * * \\
(0.007)\end{array}$ & $\begin{array}{c}0.300 \\
(0.003)\end{array}$ & $\begin{array}{c}0.588 * * * \\
(0.014)\end{array}$ & $\begin{array}{c}0.113 \\
(0.003) \\
\end{array}$ & $\begin{array}{c}0.259^{* * *} \\
(0.009)\end{array}$ & $\begin{array}{c}0.408 \\
(0.004)\end{array}$ & $\begin{array}{c}0.684 * * * \\
(0.016)\end{array}$ \\
\hline $\begin{array}{c}\text { Got into a physical } \\
\text { fight }\end{array}$ & $\begin{array}{c}0.262 \\
(0.003)\end{array}$ & $\begin{array}{c}0.498 * * * \\
(0.008)\end{array}$ & $\begin{array}{c}0.447 \\
(0.003)\end{array}$ & $\begin{array}{c}0.707 * * * \\
(0.013)\end{array}$ & $\begin{array}{c}0.345 \\
(0.004)\end{array}$ & $\begin{array}{c}0.556^{* * * *} \\
(0.011)\end{array}$ & $\begin{array}{c}0.563 \\
(0.004)\end{array}$ & $\begin{array}{c}0.777 * * * \\
(0.014)\end{array}$ \\
\hline Smokes daily & $\begin{array}{c}0.059 \\
(0.001)\end{array}$ & $\begin{array}{c}0.147 * * * \\
(0.006)\end{array}$ & $\begin{array}{c}0.085 \\
(0.002)\end{array}$ & $\begin{array}{c}0.269 * * * \\
(0.013)\end{array}$ & $\begin{array}{c}0.115 \\
(0.003)\end{array}$ & $\begin{array}{c}0.199 * * * \\
(0.008)\end{array}$ & $\begin{array}{c}0.148 \\
(0.003)\end{array}$ & $\begin{array}{c}0.351 * * * \\
(0.016)\end{array}$ \\
\hline $\mathrm{N}$ & 26,411 & 3,459 & 25,863 & 1,245 & 11,206 & 2,204 & 12,866 & 871 \\
\hline
\end{tabular}




\begin{tabular}{|c|c|c|c|c|}
\hline Selecti & and Alcoh & ple & Observable Chara & \\
\hline & & nge & $\begin{array}{l}\text { Past Year Clinic } \\
\text { Abuse or Depen }\end{array}$ & ned Alcohol \\
\hline & No Binge & Binge & No Abuse & Abuse \\
\hline Suicide Attempt & $\begin{array}{c}0.0296 \\
(0.1698) \\
\end{array}$ & $\begin{array}{l}0.1295^{*} \\
(0.3379) \\
\end{array}$ & $\begin{array}{c}0.0271 \\
(0.1626) \\
\end{array}$ & $\begin{array}{c}0.3458 * * * \\
(0.4835) \\
\end{array}$ \\
\hline & riables Inclu & rsimonious $M$ & & \\
\hline Age & $\begin{array}{l}16.7516 \\
(1.3731)\end{array}$ & $\begin{array}{c}17.3635^{* * *} \\
(1.2555)\end{array}$ & $\begin{array}{c}16.8128 \\
(1.3609)\end{array}$ & $\begin{array}{c}17.6721 * * * \\
(1.2689)\end{array}$ \\
\hline Age Squared & $\begin{array}{l}282.4964 \\
(46.5301)\end{array}$ & $\begin{array}{c}303.0489 * * * \\
(43.2016)\end{array}$ & $\begin{array}{l}284.5177 \\
(46.1545)\end{array}$ & $\begin{array}{c}313.8605^{* * *} \\
(43.9780)\end{array}$ \\
\hline Income & $\begin{array}{c}23.9770 \\
(19.8633)\end{array}$ & $\begin{array}{l}29.5810^{*} \\
(20.4159)\end{array}$ & $\begin{array}{c}25.7455 \\
(20.3523)\end{array}$ & $\begin{array}{c}16.3534 * * * \\
(13.3072)\end{array}$ \\
\hline High School Dropout & $\begin{array}{c}0.0671 \\
(0.2506)\end{array}$ & $\begin{array}{c}0.0805 \\
(0.2739)\end{array}$ & $\begin{array}{c}0.0488 \\
(0.2158)\end{array}$ & $\begin{array}{c}0.3479 * * * \\
(0.4842)\end{array}$ \\
\hline Black & $\begin{array}{c}0.1588 \\
(0.3661) \\
\end{array}$ & $\begin{array}{c}0.0212 * * * \\
(0.1451)\end{array}$ & $\begin{array}{c}0.1414 \\
(0.3489)\end{array}$ & $\begin{array}{c}0.0000 * * * \\
(0.0000)\end{array}$ \\
\hline Hispanic & $\begin{array}{c}0.1811 \\
(0.3857)\end{array}$ & $\begin{array}{c}0.0597 * * * \\
(0.2385)\end{array}$ & $\begin{array}{c}0.1515 \\
(0.3591) \\
\end{array}$ & $\begin{array}{c}0.2295 \\
(0.4275) \\
\end{array}$ \\
\hline Catholic & $\begin{array}{c}0.3079 \\
(0.4624) \\
\end{array}$ & $\begin{array}{c}0.4323^{*} \\
(0.4986) \\
\end{array}$ & $\begin{array}{c}0.3227 \\
(0.4682) \\
\end{array}$ & $\begin{array}{c}0.4629 \\
(0.5069) \\
\end{array}$ \\
\hline Protestant & $\begin{array}{c}0.5579 \\
(0.4975) \\
\end{array}$ & $\begin{array}{c}0.3870^{* *} \\
(0.4902)\end{array}$ & $\begin{array}{c}0.5388 \\
(0.4992) \\
\end{array}$ & $\begin{array}{c}0.3268 * * \\
(0.4768)\end{array}$ \\
\hline Other Religion & $\begin{array}{c}0.0453 \\
(0.2083)\end{array}$ & $\begin{array}{c}0.0888 \\
(0.2863)\end{array}$ & $\begin{array}{c}0.0549 \\
(0.2281)\end{array}$ & $\begin{array}{c}0.0411 \\
(0.2017)\end{array}$ \\
\hline Poor Health & $\begin{array}{c}0.1206 \\
(0.3263)\end{array}$ & $\begin{array}{c}0.0638 \\
(0.2460)\end{array}$ & $\begin{array}{c}0.1074 \\
(0.3100)\end{array}$ & $\begin{array}{c}0.1359 \\
(0.3484)\end{array}$ \\
\hline Urban & $\begin{array}{c}0.7971 \\
(0.4029) \\
\end{array}$ & $\begin{array}{c}0.8578 \\
(0.3515) \\
\end{array}$ & $\begin{array}{c}0.8021 \\
(0.3990) \\
\end{array}$ & $\begin{array}{l}0.9028^{*} \\
(0.3011) \\
\end{array}$ \\
\hline & onal Variab & ed in Extendeo & & \\
\hline Past Year Mental Illness & $\begin{array}{c}0.4067 \\
(0.4921) \\
\end{array}$ & $\begin{array}{c}0.5267 \\
(0.5025) \\
\end{array}$ & $\begin{array}{c}0.4019 \\
(0.4910) \\
\end{array}$ & $\begin{array}{c}0.8110 * * * \\
(0.3980)\end{array}$ \\
\hline No Seat belt & $\begin{array}{c}0.0414 \\
(0.1994) \\
\end{array}$ & $\begin{array}{c}0.0828 \\
(0.2773) \\
\end{array}$ & $\begin{array}{c}0.0368 \\
(0.1885) \\
\end{array}$ & $\begin{array}{l}0.2196^{*} \\
(0.4208) \\
\end{array}$ \\
\hline No Condom & $\begin{array}{c}0.0974 \\
(0.2970)\end{array}$ & $\begin{array}{c}0.1121 \\
(0.3175)\end{array}$ & $\begin{array}{c}0.0962 \\
(0.2953)\end{array}$ & $\begin{array}{c}0.1536 \\
(0.3666)\end{array}$ \\
\hline Parents & $\begin{array}{c}0.6077 \\
(0.4891) \\
\end{array}$ & $\begin{array}{c}0.5633 \\
(0.4991) \\
\end{array}$ & $\begin{array}{c}0.6146 \\
(0.4874) \\
\end{array}$ & $\begin{array}{c}0.3905^{* *} \\
(0.4959)\end{array}$ \\
\hline Fire & $\begin{array}{c}0.0961 \\
(0.2952)\end{array}$ & $\begin{array}{c}0.1322 \\
(0.3409)\end{array}$ & $\begin{array}{c}0.0992 \\
(0.2994)\end{array}$ & $\begin{array}{c}0.1572 \\
(0.3700)\end{array}$ \\
\hline Abused & $\begin{array}{c}0.0305 \\
(0.1723)\end{array}$ & $\begin{array}{c}0.0959 \\
(0.2963)\end{array}$ & $\begin{array}{c}0.0306 \\
(0.1726)\end{array}$ & $\begin{array}{l}0.2142 * * \\
(0.4170)\end{array}$ \\
\hline Raped & $\begin{array}{c}0.0715 \\
(0.2581)\end{array}$ & $\begin{array}{c}0.1505 \\
(0.3598)\end{array}$ & $\begin{array}{c}0.0715 \\
(0.2581)\end{array}$ & $\begin{array}{l}0.2943^{*} \\
(0.4633)\end{array}$ \\
\hline Molested & $\begin{array}{c}0.0886 \\
(0.2846) \\
\end{array}$ & $\begin{array}{c}0.1161 \\
(0.3223) \\
\end{array}$ & $\begin{array}{c}0.0951 \\
(0.2938) \\
\end{array}$ & $\begin{array}{c}0.0801 \\
(0.2760) \\
\end{array}$ \\
\hline Shock & $\begin{array}{c}0.1846 \\
(0.3887) \\
\end{array}$ & $\begin{array}{c}0.1956 \\
(0.3992) \\
\end{array}$ & $\begin{array}{c}0.1722 \\
(0.3781) \\
\end{array}$ & $\begin{array}{l}0.3807 * \\
(0.4936) \\
\end{array}$ \\
\hline Death of Relative & $\begin{array}{c}0.3046 \\
(0.4610)\end{array}$ & $\begin{array}{c}0.2738 \\
(0.4488)\end{array}$ & $\begin{array}{c}0.2827 \\
(0.4510)\end{array}$ & $\begin{array}{c}0.5091 * * \\
(0.5082)\end{array}$ \\
\hline Crisis & $\begin{array}{c}0.2427 \\
(0.4295) \\
\end{array}$ & $\begin{array}{c}0.3034 \\
(0.4627)\end{array}$ & $\begin{array}{c}0.2467 \\
(0.4317) \\
\end{array}$ & $\begin{array}{c}0.3625 \\
(0.4887)\end{array}$ \\
\hline Observations & 294 & 79 & 342 & 31 \\
\hline
\end{tabular}




\begin{tabular}{|c|c|c|}
\hline \multicolumn{3}{|c|}{$\begin{array}{c}\text { Table 4 } \\
\text { NCS Sample } \\
\text { Girls } \\
\text { Selection into Suicide Attempt on Observable Characteristics } \\
\text { Mean } \\
\text { (Standard Error) } \\
\end{array}$} \\
\hline & No Attempt & Attempt \\
\hline Binge Drinking & $\begin{array}{c}0.1816 \\
(0.3860)\end{array}$ & $\begin{array}{l}0.5197^{*} \\
(0.5185)\end{array}$ \\
\hline Alcohol Use Disorder & $\begin{array}{c}0.0482 \\
(0.2144) \\
\end{array}$ & $\begin{array}{c}0.4899^{* * *} \\
(0.5188)\end{array}$ \\
\hline \multicolumn{3}{|c|}{ Variables Included in Parsimonious Model } \\
\hline Age & $\begin{array}{c}16.8354 \\
(1.3557)\end{array}$ & $\begin{array}{c}17.5961 * * \\
(1.5144)\end{array}$ \\
\hline Age Squared & $\begin{array}{l}285.2627 \\
(45.9931)\end{array}$ & $\begin{array}{c}311.7516^{* *} \\
(52.0281)\end{array}$ \\
\hline Income & $\begin{array}{c}25.4877 \\
(20.2193)\end{array}$ & $\begin{array}{c}17.4001^{*} \\
(15.6410)\end{array}$ \\
\hline High School Dropout & $\begin{array}{c}0.0563 \\
(0.2309) \\
\end{array}$ & $\begin{array}{l}0.3277^{*} \\
(0.4871) \\
\end{array}$ \\
\hline Black & $\begin{array}{c}0.1306 \\
(0.3375)\end{array}$ & $\begin{array}{c}0.1479 \\
(0.3684)\end{array}$ \\
\hline Hispanic & $\begin{array}{c}0.1481 \\
(0.3557)\end{array}$ & $\begin{array}{c}0.3277 \\
(0.4871)\end{array}$ \\
\hline Catholic & $\begin{array}{c}0.3306 \\
(0.4711) \\
\end{array}$ & $\begin{array}{c}0.3710 \\
(0.5013) \\
\end{array}$ \\
\hline Protestant & $\begin{array}{c}0.5309 \\
(0.4997)\end{array}$ & $\begin{array}{c}0.3912 \\
(0.5064)\end{array}$ \\
\hline Other Religion & $\begin{array}{c}0.0500 \\
(0.2183)\end{array}$ & $\begin{array}{c}0.1291 \\
(0.3480)\end{array}$ \\
\hline Poor Health & $\begin{array}{c}0.1078 \\
(0.3106)\end{array}$ & $\begin{array}{c}0.1396 \\
(0.3597)\end{array}$ \\
\hline Urban & $\begin{array}{c}0.8022 \\
(0.3989) \\
\end{array}$ & $\begin{array}{l}0.9421^{*} \\
(0.2425) \\
\end{array}$ \\
\hline \multicolumn{3}{|c|}{ Additional Variables Included in Extended Model } \\
\hline Past Year Mental Illness & $\begin{array}{c}0.4076 \\
(0.4921) \\
\end{array}$ & $\begin{array}{c}0.8709 * * * \\
(0.3479)\end{array}$ \\
\hline No Seat belt & $\begin{array}{c}0.0390 \\
(0.1938) \\
\end{array}$ & $\begin{array}{l}0.2532^{*} \\
(0.4513) \\
\end{array}$ \\
\hline No Condom & $\begin{array}{c}0.0948 \\
(0.2934)\end{array}$ & $\begin{array}{c}0.2111 \\
(0.4248)\end{array}$ \\
\hline Parents & $\begin{array}{c}0.6200 \\
(0.4861)\end{array}$ & $\begin{array}{c}0.1934 * * * \\
(0.4099)\end{array}$ \\
\hline Fire & $\begin{array}{c}0.0935 \\
(0.2915)\end{array}$ & $\begin{array}{c}0.2918 \\
(0.4718)\end{array}$ \\
\hline Abused & $\begin{array}{c}0.0304 \\
(0.1719)\end{array}$ & $\begin{array}{c}0.2954 \\
(0.4734)\end{array}$ \\
\hline Raped & $\begin{array}{c}0.0692 \\
(0.2542)\end{array}$ & $\begin{array}{c}0.4314 * * * \\
(0.5140)\end{array}$ \\
\hline Molested & $\begin{array}{c}0.0917 \\
(0.2890)\end{array}$ & $\begin{array}{c}0.1391 \\
(0.3591)\end{array}$ \\
\hline Shock & $\begin{array}{c}0.1761 \\
(0.3814)\end{array}$ & $\begin{array}{c}0.3928 \\
(0.5068)\end{array}$ \\
\hline Death of Relative & $\begin{array}{c}0.2811 \\
(0.4502)\end{array}$ & $\begin{array}{c}0.6326^{* *} \\
(0.5003)\end{array}$ \\
\hline Crisis & $\begin{array}{c}0.2501 \\
(0.4337)\end{array}$ & $\begin{array}{c}0.3451 \\
(0.4933)\end{array}$ \\
\hline Observations & 359 & 14 \\
\hline
\end{tabular}




\begin{tabular}{|c|c|c|c|c|c|c|c|c|}
\hline & & & Table & & & & & \\
\hline & & & RBS SA & LE & & & & \\
\hline & $\begin{array}{r}\text { EFF } \\
\text { OP }\end{array}$ & $\begin{array}{l}\text { T OF BIN } \\
\text { NY SUICI }\end{array}$ & $\begin{array}{l}\text { E DRINK } \\
\text { E ATTE }\end{array}$ & $\begin{array}{l}\text { TG IN PA } \\
\text { TS IN P }\end{array}$ & $\begin{array}{l}\text { T MONT } \\
\text { ST YEAR }\end{array}$ & & & \\
\hline & & & $\begin{array}{l}\text { Marginal } \\
\text { (T-rati }\end{array}$ & & & & & \\
\hline & & $\begin{array}{r}\text { Full S } \\
\text { rinkers and }\end{array}$ & $\begin{array}{l}\text { nple: } \\
\text { on-Drink }\end{array}$ & & & Drinkers & nly Samp & \\
\hline & & irls & & & & $\mathrm{rls}$ & & \\
\hline & $\begin{array}{c}\text { Small } \\
\text { Set }\end{array}$ & Big Set & $\begin{array}{c}\text { Small } \\
\text { Set }\end{array}$ & Big Set & $\begin{array}{c}\text { Small } \\
\text { Set }\end{array}$ & Big Set & $\begin{array}{c}\text { Small } \\
\text { Set }\end{array}$ & Big Set \\
\hline Probit & $\begin{array}{l}0.117 \\
(25.03) \\
\end{array}$ & $\begin{array}{l}0.068 \\
(14.90) \\
\end{array}$ & $\begin{array}{l}0.049 \\
(17.24) \\
\end{array}$ & $\begin{array}{l}0.018 \\
(7.06) \\
\end{array}$ & $\begin{array}{l}0.082 \\
(12.53) \\
\end{array}$ & $\begin{array}{l}0.052 \\
(7.89) \\
\end{array}$ & $\begin{array}{l}0.045 \\
(10.47) \\
\end{array}$ & $\begin{array}{l}0.025 \\
(6.00) \\
\end{array}$ \\
\hline & & & riate Prob & Models & & & & \\
\hline (1) $\mathrm{Rho}=.1$ & & $\begin{array}{l}0.033 \\
(7.61) \\
\end{array}$ & & $\begin{array}{l}0.004 \\
(1.39) \\
\end{array}$ & & $\begin{array}{l}0.022 \\
(2.79) \\
\end{array}$ & & $\begin{array}{l}0.005 \\
(1.11) \\
\end{array}$ \\
\hline (2) $\mathrm{Rho}=.2$ & & $\begin{array}{l}0.001 \\
(0.200)\end{array}$ & & $\begin{array}{l}-0.009 \\
(-3.48)\end{array}$ & & $\begin{array}{l}-0.018 \\
(-2.40)\end{array}$ & & $\begin{array}{l}-0.013 \\
(-2.95)\end{array}$ \\
\hline (3) $\mathrm{Rho}=.3$ & & $\begin{array}{l}-0.028 \\
(-7.39)\end{array}$ & & $\begin{array}{l}-0.021 \\
(-8.49)\end{array}$ & & $\begin{array}{l}-0.056 \\
(-7.76)\end{array}$ & & $\begin{array}{l}-0.032 \\
(-7.21)\end{array}$ \\
\hline (4) $\mathrm{Rho}=.4$ & & $\begin{array}{l}-0.056 \\
(-15.35)\end{array}$ & & $\begin{array}{l}-0.033 \\
(-13.77)\end{array}$ & & $\begin{array}{l}-0.094 \\
(-13.40)\end{array}$ & & $\begin{array}{l}-0.055 \\
(-11.77)\end{array}$ \\
\hline (5) $\mathrm{Rho}=.5$ & & $\begin{array}{l}-0.082 \\
(-23.91)\end{array}$ & & $\begin{array}{l}-0.625 \\
(-19.50)\end{array}$ & & $\begin{array}{l}-0.131 \\
(-19.48)\end{array}$ & & $\begin{array}{l}-0.083 \\
(-16.83)\end{array}$ \\
\hline $\begin{array}{l}\text { (6) Selection on } \\
\text { observables = selection } \\
\text { on unobservables } \\
\text { (excludes small set) }\end{array}$ & & Rho $>1$ & & Rho $>1$ & & $\begin{array}{l}-0.232 \\
(-36.01) \\
\text { Rho }= \\
0.658 \\
\end{array}$ & & $\begin{array}{l}-0.373 \\
(-50.40) \\
\text { Rho }= \\
0.863 \\
\end{array}$ \\
\hline $\mathrm{N}$ & & 29,870 & & 27,108 & & 13,410 & & 13,737 \\
\hline F Test Statistic & & $\begin{array}{r}\mathrm{F}(14,56,9 \\
\text { Prob }>\mathrm{F}\end{array}$ & $\begin{array}{l}=89.78 \\
0.0000\end{array}$ & & & $\begin{array}{r}\mathrm{F}(14,27,1 \\
\text { Prob }>1\end{array}$ & $\begin{array}{l}8)=65.2 \\
=0.0000\end{array}$ & \\
\hline
\end{tabular}

NOTE: The small set includes age, region, survey year, state unemployment, and state real income. The big set includes age, region, survey year, state unemployment, state real income, grade, plays on at least one sports team, smokes daily, wears seat belts often, physical fight in past year, and carried a weapon in past year. 


\begin{tabular}{|c|c|c|c|c|}
\hline \multicolumn{5}{|c|}{ Table 6} \\
\hline \multicolumn{5}{|c|}{ NCS SAMPLE } \\
\hline \multicolumn{5}{|c|}{ GIRLS } \\
\hline \multicolumn{5}{|c|}{$\begin{array}{l}\text { EFFECT OF ALCOHOL ABUSE IN PAST YEAR } \\
\text { ON ANY SUICIDE ATTEMPTS IN PAST YEAR }\end{array}$} \\
\hline \multicolumn{5}{|c|}{$\begin{array}{l}\text { Marginal Effect } \\
\quad \text { (T-Ratio) }\end{array}$} \\
\hline Model & \multicolumn{2}{|c|}{ Binge Drinking } & \multicolumn{2}{|c|}{ Alcohol Use Disorder } \\
\hline & Small Set & Big Set & Small Set & Big Set \\
\hline Probit & $\begin{array}{c}0.0782 \\
(3.57) \\
\end{array}$ & $\begin{array}{c}0.0083 \\
(2.16) \\
\end{array}$ & $\begin{array}{c}0.1838 \\
(4.79) \\
\end{array}$ & $\begin{array}{l}0.0387 \\
(3.39) \\
\end{array}$ \\
\hline \multicolumn{5}{|c|}{ Bivariate Probit Models } \\
\hline (1) $\mathrm{Rho}=.1$ & & $\begin{array}{c}0.0054 \\
(1.66) \\
\end{array}$ & & $\begin{array}{l}0.0272 \\
(3.03) \\
\end{array}$ \\
\hline (2) $\mathrm{Rho}=.2$ & & $\begin{array}{c}0.0033 \\
(1.16) \\
\end{array}$ & & $\begin{array}{l}0.0189 \\
(2.67) \\
\end{array}$ \\
\hline (3) $\mathrm{Rho}=.3$ & & $\begin{array}{c}0.0016 \\
(0.63)\end{array}$ & & $\begin{array}{l}0.0129 \\
(2.30)\end{array}$ \\
\hline (4) $\mathrm{Rho}=.4$ & & $\begin{array}{l}0.0002 \\
(0.08)\end{array}$ & & $\begin{array}{l}0.0087 \\
(1.91)\end{array}$ \\
\hline (5) $\mathrm{Rho}=.5$ & & $\begin{array}{c}-0.0014 \\
(-0.53) \\
\end{array}$ & & $\begin{array}{l}0.0056 \\
(1.50)\end{array}$ \\
\hline $\begin{array}{l}\text { (6) Selection on observables = } \\
\text { selection on unobservables } \\
\text { (excludes small set) }\end{array}$ & & $\begin{array}{c}0.0035 \\
(1.21) \\
\text { Rho }=0.189\end{array}$ & & $\begin{array}{c}0.0126 \\
(2.27) \\
\text { Rho }=0.307\end{array}$ \\
\hline $\mathrm{N}$ & \multicolumn{2}{|c|}{364} & \multicolumn{2}{|c|}{364} \\
\hline
\end{tabular}

NOTE: The small set includes: age, age squared, income, high school dropout, black, hispanic, catholic, protestant, other religion, poor health, and urban. The big set includes age, age squared, income, high school dropout, black, hispanic, catholic, protestant, other religion, poor health, urban, past year mental illness, no seat belt, no condom, fire, abused, raped, molested, shock, death of relative, and crisis. 